\title{
Spécificités de la santé animale en régions chaudes : le cas des maladies infectieuses majeures en Afrique
}

\author{
R. LANCELOT $1,2, E . Z U N D E L^{3}$, C. DUCROT 4 \\ ${ }^{1}$ CIRAD, Contrôle des maladies animales exotiques et émergentes, \\ Campus International de Baillarguet, F-34398 Montpellier, France \\ 2 INRA, UMR1309, Contrôle des maladies animales exotiques et émergentes, \\ Campus International de Baillarguet, F-34398 Montpellier, France \\ 3 INRA, Département Santé Animale, F-37380 Nouzilly, France \\ ${ }^{4}$ INRA,Unité d'épidémiologie animale, F-63122 Saint-Genès-Champanelle, France \\ Courriel : renaud.lancelot@cirad.fr
}

A partir d'exemples pris en Afrique, cet article vise à montrer en quoi les pays en développement des régions chaudes du Sud, sont confrontés à des maladies animales infectieuses et parasitaires qui nécessitent une approche coordonnée aux plans régional et international, avec des mesures adaptées à leurs conditions socio-économiques et environnementales spécifiques, pour leur propre bénéfice et celui de l'ensemble de la planète.

Les régions chaudes, comme toutes les régions du globe, sont confrontées à des maladies animales infectieuses et parasitaires qui représentent des contraintes économiques et/ou des risques pour la santé publique humaine. Ces problèmes sanitaires évoluent au fil du temps, sous l'effet des changements environnementaux et socio-économiques qui aboutissent à des modifications des populations animales et des systèmes d'élevage, ainsi que des flux d'animaux et de produits animaux.

Dans cet article, nous nous sommes délibérément limités au cas de l'Afrique, exemplaire pour ses régions chaudes et leur évolution climatique, préoccupante en raison de la taille de ce continent, de sa croissance démographique rapide, de ses fortes contraintes environnementales et socio-économiques, et des difficultés politiques qu'il rencontre. Ces multiples contraintes aboutissent à une maîtrise insuffisante des maladies infectieuses et parasitaires.

Nous avons également pris le parti de ne présenter que de grandes maladies infectieuses à fort impact économique ou de santé publique, et dont le contrôle nécessite un effort international et une coordination adéquate. Elles correspondent à la définition donnée par la FAO des maladies transfrontalières ${ }^{1}$. Nous avons choisi quelques exemples de maladies majeures, dont l'épidémiologie est déterminée soit par la mobilité animale (commerce, transhumance) et le système d'élevage, soit par des conditions environnementales particulières. Ces deux types de maladies sont abordés séparément dans la présentation par souci de clarté de l'exposé, même si certaines maladies relèvent à la fois de l'un et de l'autre (maladies parasitaires, à transmission vectorielle...). Nous avons ensuite tenté de dégager des perspectives d'évolution et des défis à relever en matière de recherche et d'appui scientifique et technique aux services vétérinaires.

Ce point de vue exclut de fait de nombreuses autres pathologies dont il n'est pas question de contester le fort impact économique et sanitaire : parasitisme interne et externe, zoonoses hydriques et alimentaires, alimentation, combinaisons de facteurs, etc.

\section{1 / Mobilité et santé des animaux}

Une des particularités de l'élevage en Afrique est la pratique du pastoralisme et de la transhumance à grande échelle, système d'élevage permettant de valoriser les herbages saisonniers et les faibles ressources fourragères sur les terres arides et semi-arides. Dans les pays sahéliens, le pastoralisme représente 70 à $90 \%$ de l'élevage bovin et 30 à $40 \%$ de l'élevage de petits ruminants (Kamuanga et al 2008). Cette transhumance dépasse les frontières des états et favorise la diffusion des maladies contagieuses. De plus, le développement démographique et économique fait émerger des mégalopoles (Le Caire, Lagos) et des régions à forte densité de population (Nord du Maghreb et du Machreq, Golfe de Guinée, Région des Grands Lacs) qui sont autant de centres de consommation de produits animaux, suscitant ainsi des flux commerciaux toujours croissant d'animaux sur pied ou de leurs produits (Alary 2006). Dans un tel contexte, une structuration forte des services vétérinaires, l'existence de

${ }^{1}$ La FAO définit les maladies transfrontalières (Transboundary Animal Diseases - TAD) comme des maladies d'une importance significative pour l'économie, le commerce et/ou la sécurité alimentaire d'un ensemble de pays. Elles peuvent se propager facilement à d'autres pays et atteindre des proportions épizootiques. Leur contrôle et leur éradication nécessitent une coopération internationale. Traduction libre d'après www.rlc.fao.org/en/prioridades/transfron; Accès 2011.03.22. Voir aussi www.fao.org/AG/AGAInfo/programmes/en/empres/diseases.asp. 
relais de terrain efficaces, et une concertation étroite entre états sont une nécessité pour contrôler et éradiquer les maladies contagieuses réglementées, alors que le contexte socio-économique difficile de nombre d'états africains ne permet pas une telle organisation. Il s'ensuit que nombre de maladies contagieuses éradiquées en Europe continuent de circuler en Afrique.

\section{1 / Ruminants}

La peste bovine, due à un Morbillivirus d'origine asiatique, est emblématique des questions d'épidémiologie et de contrôle des maladies liées à la mobilité animale en Afrique. Des mouvements commerciaux de bétail sont à l'origine de son introduction en Afrique à plusieurs reprises, au moins en Egypte et en Erythrée (Mack 1970). Des importations de zébus indiens par l'armée italienne en Erythrée en 1887 et 1889, puis la diffusion du virus par les transhumances et les mouvements régionaux commerciaux de bétail, sont ainsi à l'origine d'une panzootie qui a ravagé les populations de bovidés domestiques et sauvages du continent en plusieurs vagues successives, causant une mortalité allant jusqu'à $90 \%$ des populations atteintes, et consécutivement, nombre de famines et troubles sociaux.

Il a fallu la mise au point du vaccin atténué sur culture cellulaire de Plowright (Plowright et Ferris 1962) pour envisager des campagnes de vaccination de masse à l'échelle du continent africain puis la mise en place progressive d'un programme mondial d'éradication de la peste bovine coordonné par l'Organisation des Nations Unies pour l'alimentation et l'agriculture (FAO) et l'Organisation mondiale pour la santé animale (OIE), et bénéficiant de financements internationaux (Mukhopadhyay et al 1999).

C'est en Afrique que l'éradication fut la plus difficile à atteindre, avec des zones infectées difficiles d'accès à cause de leur éloignement et/ou les conflits y sévissant, et l'existence de possibles réservoirs sauvages. Centré sur des campagnes de vaccination de masse, ce programme a intégré des études d'évaluation de l'efficacité des campagnes de vaccination et du rôle de la faune sauvage dans la persistance du virus dans l'environnement (CouacyHymann et al 2005, Kock et al 2006, Rossiter et al 2006). Des enquêtes épidémiologiques ont été élaborées, harmonisées et étendues à l'ensemble des pays concernés (Mariner et al 2003). Des stratégies spécifiques de surveillance et de vaccination ont été mises en place pour les zones difficiles comme l'écosystème Somali, où la mobilité animale était forte en réponse à la disponibilité variable dans l'espace et le temps de ressources fourragères et hydriques (transhumance), avec une économie familiale et régionale dépendant étroitement du commerce du bétail (Knips 2004). D'autre part, les conditions de sécurité empêchaient l'intervention des services vétérinaires officiels. Cette stratégie s'est appuyée sur le développement d'un vaccin thermostable pour s'affranchir de la chaîne du froid, ainsi que sur le recours à des auxiliaires vétérinaires issus des communautés d'éleveurs pour administrer le vaccin aux bovins (Mariner et Roeder 2003).

$\mathrm{Au}$ final, la peste bovine a été éradiquée d'Afrique et du reste du monde : la déclaration officielle devrait intervenir en 2011 et n'est retardée que par des questions de recensement et de gestion des souches du virus détenues par les laboratoires de référence (Normile 2008). Ce succès remarquable est le seul exemple d'éradication d'un virus en médecine vétérinaire, et le second après le virus de la variole. L'aide internationale (environ 280 millions d' $€$ ) a somme toute été modeste au regard des efforts consentis par les services vétérinaires nationaux et des bénéfices obtenus. Les clés de la réussite, notamment pour la phase finale de l'éradication, toujours la plus difficile, ont été i) la disponibilité d'un vaccin efficace, ii) l'aide financière et la coordination internationale, et iii) l'adaptation des mesures de surveillance et de contrôle aux spécificités des écosystèmes africains et des systèmes d'élevage les exploitant, basée sur un appui stratégique aux services vétérinaires chargés de la lutte. Il convient de noter qu'audelà de la lutte contre la peste bovine, ces programmes internationaux ont permis le renforcement des services vétérinaires africains et de leurs capacités de surveillance et de contrôle des maladies animales, servant ainsi de support à leur modernisation jusque dans les aspects de privatisation de la profession.

Un autre Morbillivirus, causant la peste des petits ruminants (PPR), est largement répandu en Afrique, au Moyen Orient et en Asie. Pour ce dernier continent, le Maroc, la Tanzanie et la Tunisie ont été nouvellement trouvés infectés (Sanz-Alvarez et al 2008, Swai et al 2009, Ayari-Fakhfakh et al 2011). La PPR est considérée comme la maladie impactant le plus l'élevage des petits ruminants avec des pertes de productivité de 50 à $90 \%$ et des taux de létalité de 10 à $90 \%$ éventuellement augmentés lors de maladies intercurrentes (AU-IBAR 2011). Par ailleurs, l'expression clinique émerge chez le dromadaire depuis quelques années, avec des cas cliniques avérés au Soudan (Khalafalla et al 2010), alors que jusqu'à présent, les suspicions n'avaient pu être confirmées formellement (Roger et al 2001, Abraham et al 2005). Enfin, des enquêtes épidémiologiques et virologiques récentes effectuées au Maroc, au Sénégal et au Soudan montrent que de profonds changements s'opèrent en matière de distribution géographique des lignées virales du virus de la PPR, par rapport aux descriptions antérieures (Shaila et al 1996). Selon toute vraisemblance, ces changements sont en relation avec l'intensification des échanges commerciaux régionaux et interrégionaux sous l'influence de l'accroissement démographique et de la croissance des besoins humains en protéines animales, mais également en réponse aux crises climatiques telles que les sécheresses récurrentes en Afrique sahélienne, dans la corne de l'Afrique et en Afrique australe, parfois suivies d'inondations catastrophiques sous l'influence du phénomène El Niño.

Malgré l'existence d'un vaccin homologue efficace (Diallo et al 1989) et de méthodes modernes et rapides de diagnostic, le virus de la PPR est en extension géographique. Les informations $i$ ) épidémiologiques sur l'occurrence des foyers de PPR et la caractérisation précise des virus, et $i i)$ socio-économiques sur les mouvements animaux et leurs déterminants sont toutefois encore trop incomplètes pour orienter efficacement la lutte contre la PPR. A l'instar de ce qui s'est produit pour la peste bovine, une mobilisation internationale est nécessaire pour établir une stratégie de lutte basée sur un vaccin de nouvelle génération permettant de distinguer les anticorps induits par la vaccination de ceux consécutifs à une infection. Audelà du vaccin, les défis sont d'établir une connaissance opérationnelle des mouvements animaux liés au commerce et à l'utilisation de l'espace pastoral, et d'associer éleveurs et services vétérinaires à la définition d'une stratégie vaccinale sur le long terme, compte tenu de la très large distribution actuelle du virus en Afrique, au Moyen-Orient et en Asie.

Parmi les autres maladies des ruminants, la fièvre aphteuse et les mycoplasmoses respiratoires (péripneumonie contagieuse bovine (PPCB) et pleuropneumonie contagieuse caprine (PPCC)) sont endémiques en Afrique et posent des problèmes difficiles à résoudre. En effet, les ruminants sauvages constituent un réservoir du virus de la fièvre aphteuse - à la différence de la peste bovine et de la PPR - à l'origine de résurgences de la maladie chez le bétail y compris dans des régions protégées des contacts avec la faune sauvage par 
des clôtures ad hoc, comme en Afrique australe (Bastos et al 2000, Hargreaves et al 2004). La prise en compte du rôle de la faune sauvage dans la persistance et la transmission du virus, et la mise en place de mesures correctives acceptables sur les plans de la société et de la biodiversité, représentent de grands défis pour les programmes internationaux de lutte contre la fièvre aphteuse. En effet, le continent africain présente de grandes populations de ruminants sauvages en contact avec des ruminants domestiques détenus par des pasteurs eux-mêmes très mobiles.

Pour la PPCB, avec des pertes économiques annuelles estimées à 2 milliards USD (AU-IBAR 2011), comme pour la PPCC, l'absence conjointe de vaccin performant et de test diagnostique capable de différencier les anticorps produits par l'infection naturelle ou la vaccination, sont des handicaps majeurs pour la lutte (Thiaucourt et al 2003, Nicholas et al 2009). D'autre part, en corollaire de l'éradication de la peste bovine, plus aucune campagne de vaccination de masse des bovins n'est entreprise à l'échelle africaine. On a ainsi récemment assisté à une résurgence de la PPCB dont la situation épidémiologique est méconnue en l'absence de surveillance systématique de la maladie. Cette situation est d'autant plus floue que les éleveurs n'hésitent plus à recourir à des traitements antibiotiques même s'ils ne peuvent blanchir les animaux et risquent ainsi de concourir au maintien de l'infection dans les populations bovines (Thiaucourt et al 2004, Hübschle et al 2006).

\section{2 / Porcins}

La peste porcine africaine (PPA) avec un taux de létalité généralement proche de $100 \%$, constitue le risque actuel le plus grave pour l'élevage porcin du continent alors que les perspectives de disponibilité d'un vaccin sont encore lointaines. Par exemple, l'épizootie de 1982 au Cameroun avait tué $80 \%$ de la population porcine nationale estimée à 1,6 millions de porcs. La PPA est causée par un Asfivirus à ADN très résistant dans les produits issus des porcs infectés et dans le milieu extérieur, et susceptible de transmission vectorielle par diverses espèces de tiques molles du genre Ornithodoros. Des cycles sauvages existent dans les populations africaines de suidés sauvages, avec l'intervention probable de la transmission vectorielle (Jori et Bastos 2009).

Toutefois, les voies d'introduction et de diffusion du virus de la PPA dans les populations domestiques sont multiples : contact direct entre porcs ou avec des suidés sauvages dans des systèmes
Figure 1. Foyers de peste porcine africaine déclarés à l'OIE de janvier 2004 à décembre 2010 (continuing : en cours ; resolved : terminé). Source : OIE, WAHID, 2010 (accès le 11/12/2010).

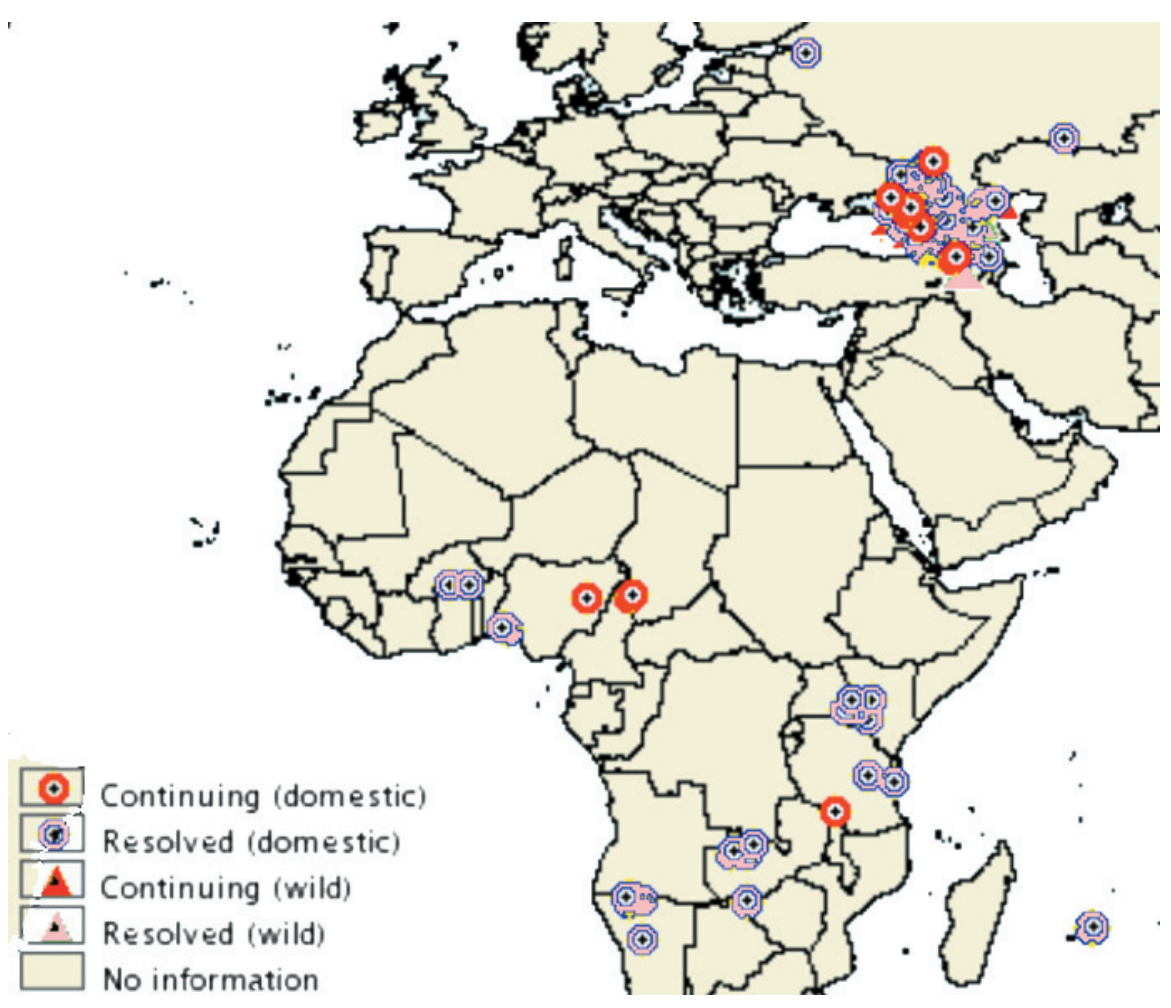

d'élevage sur parcours naturels ou cultivés (forêts, rizières...), consommation d'aliments ou autres intrants souillés par le virus, ou morsure par des tiques infectées. Consécutivement, la transmission et la diffusion de la PPA sont surtout liées au commerce des porcs et produits porcins, à des mesures de biosécurité défaillantes, et à l'élevage en divagation. Le virus de la PPA se maintient ainsi dans des agro-écosystèmes où les tiques vectrices sont absentes, comme dans certaines zones de Madagascar (Ravaomanana et al 2010).

La PPA est endémique dans tous les pays africains pratiquant la porciculture, et a récemment envahi plusieurs pays d'Europe de l'Est et la Russie, en lien avec le commerce international et le manque de rigueur dans le contrôle des mouvements d'animaux et de produits animaux. Elle a, dès la fin des années 50, fait des incursions dévastatrices en Europe, dans les Caraïbes et en Amérique du Sud où son éradication s'est avérée difficile et coûteuse. Il a fallu ainsi plus de 30 ans pour éradiquer la PPA de la péninsule ibérique, et elle reste endémique en Sardaigne, avec un élevage porcin sur parcours. En Afrique, des vagues épizootiques sévissent de temps à autre, désorganisant durablement la filière commerciale comme dans le golfe de Guinée au milieu des années 90 (el Hicheri et al 1998), ou à Madagascar lors de son introduction en 98 (Rousset et al 2001), ou encore au Cameroun, au Tchad, en République Centrafricaine et au Nigeria (épisode en cours en 2010-11). La figure 1 , où sont représentés les foyers déclarés à l'OIE, sous-estime d'ailleurs la réalité épidémiologique : de nombreux pays dans lesquels la PPA est endémique ne signalent pas les foyers. Ainsi, à Madagascar, une enquête menée en abattoir en 2004 a révélé une prévalence d'ADN viral de $14 \%$ (test PCR) sur 200 carcasses étudiées (Randriamparany et al 2005). Il est ainsi possible que faute de surveillance et de diagnostic, d'autres maladies infectieuses sévissent en Afrique sans avoir été détectées. Les foyers sudafricains de peste porcine classique (PPC) (Sandvik et al 2005) pourraient ainsi n'être que la partie émergée d'un iceberg de taille continentale.

\section{3 / Volailles}

La panzootie d'Influenza Aviaire Hautement Pathogène (IAHP) à Influenzavirus $\mathrm{A} /(\mathrm{H} 5 \mathrm{~N} 1)$ n'a pas épargné l'Afrique. Différents virus y ont été introduits au moment de la seconde vague panzootique initiée par un foyer chez les oiseaux migrateurs du lac Qinghai (Chine) en 2006 (Guan et al 2009). Parmi les 11 pays africains infectés de 2006 à 2008 (Cattoli et al 2009), le Nigeria et l'Egypte - pays peuplés et à l'aviculture développée - ont 
difficilement contrôlé l'infection. En Egypte, malgré des campagnes de vaccination aviaire de masse effectuées depuis plusieurs années, l'infection a persisté et abouti à 113 cas humains confirmés dont 37 décès de 2006 au 11 décembre 2010 (World Health Organization 2010). L'origine des virus n'a pu être déterminée avec certitude, mais il semble que les migrations d'oiseaux sauvages soient en cause dans certains cas (par exemple : Gaidet et al 2010). Quoiqu'il en soit, les mouvements commerciaux d'oiseaux domestiques et de produits aviaires, associés à des mesures défaillantes de biosécurité, ont abouti à une diffusion locale et régionale rapide du virus (Aly et al 2008, Fasina et al 2009). Sa persistance pose d'évidents problèmes de santé publique humaine et vétérinaire, allant de l'apparition de souches virales résistantes aux antiviraux jusqu'au risque de recombinaison avec d'autres Influenzavirus. En effet, le delta du Nil est à la fois une région de forte circulation du virus $\mathrm{A} /(\mathrm{H} 5 \mathrm{~N} 1)$ et une zone d'hivernage et de passage pour des millions d'oiseaux migrateurs (Saad et al 2007, Abdelwhab et al 2010). Cette situation marque l'échec des campagnes de vaccination de masse menées jusqu'à présent (Peyre et al 2009, Hafez et al 2010). Il est nécessaire de définir et appliquer une nouvelle stratégie de surveillance et de contrôle de l'IAHP dans ce pays, y compris le type de vaccin et le calendrier vaccinal utilisés (Kim et al 2010).

Alors que la diffusion de l'IAHP est restée limitée à l'échelle de l'Afrique, la maladie de Newcastle est largement répandue et occasionne de lourdes pertes économiques dans les petits élevages familiaux (Maho et al 2004, Maminiaina et al 2007). Les élevages modernes sont plus faciles à protéger par des mesures de vaccination qui restent a priori efficaces malgré l'introduction durant la dernière décennie de nouveaux génotypes viraux d'origine asiatique (Bwala et al 2009, Hassan et al 2010). Un effet collatéral de l'émergence de l'IAHP A/(H5N1) en Afrique a été de redynamiser les travaux de recherche sur la maladie de Newcastle, dont l'épidémiologie et l'expression clinique sont semblables. En effet, grâce aux moyens mis en œuvre pour la surveillance de l'IAHP, de nombreux oiseaux sauvages ont été prélevés et des suspicions cliniques de pestes aviaires en élevages ont été investiguées, aboutissant à la caractérisation et à l'isolement de virus de la maladie de Newcastle. Il est ainsi apparu que des génotypes viraux jusqu'alors inconnus circulent dans des régions contrastées aux plans agro-écologiques et des systèmes d'élevage, comme le Mali ou

Figure 2. Probabilité de présence des glossines (groupes Fusca, Morsitans, Palpalis) responsables de la transmission des agents des trypanosomoses africaines animales et humaines, prédite par le modèle de Wint et Rogers (2002). L'échelle de probabilité est donnée à droite de la carte.

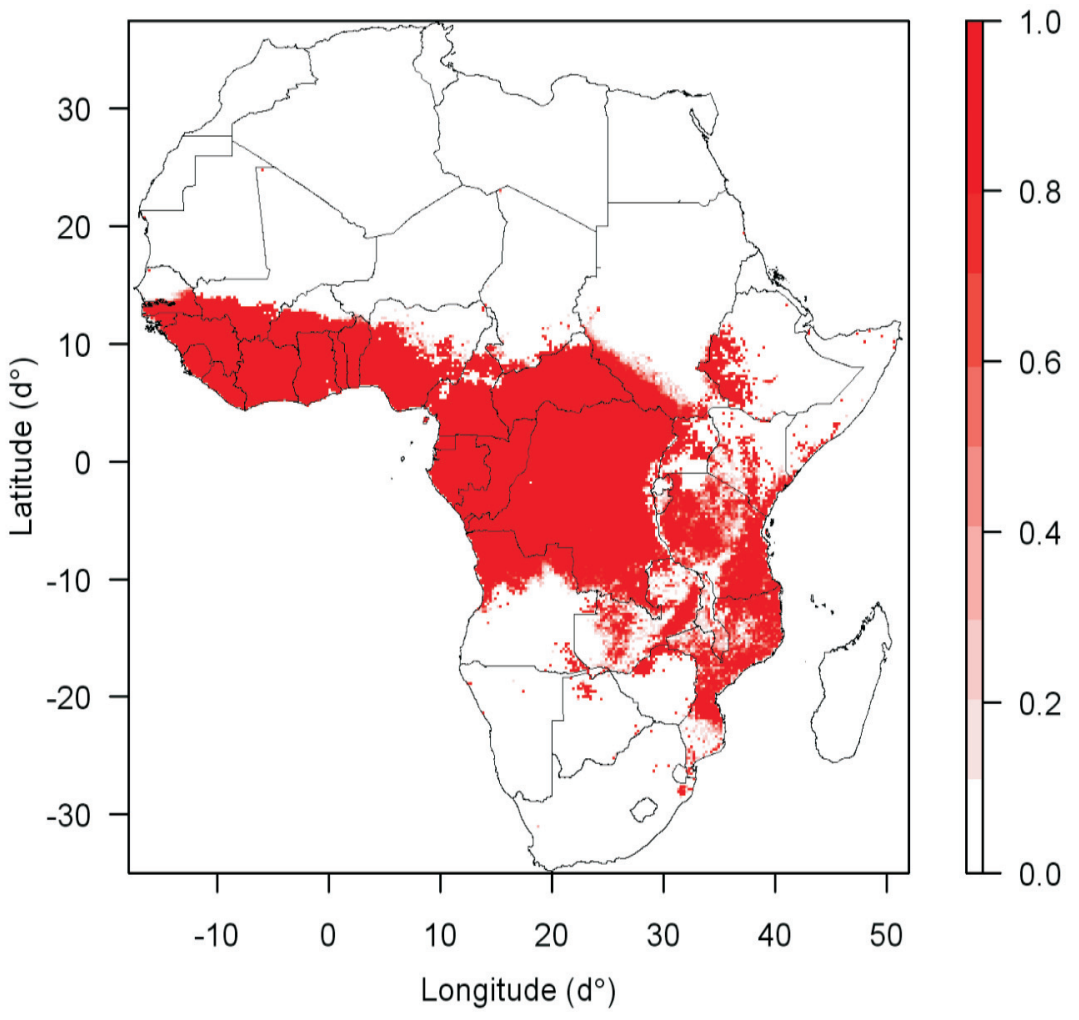

Madagascar (Cattoli et al 2010, Maminiaina et al 2010). Compte tenu de l'aspect fragmentaire des informations disponibles, il est possible que d'autres génotypes non identifiés circulent: il est important pour l'élevage africain et mondial de mieux connaître la distribution de ces virus dans l'avifaune sauvage et domestique, de caractériser leur pouvoir pathogène et de vérifier l'adéquation des vaccins existants.

\section{2 / Conditions environne- mentales et agents pathogè- nes à transmission vecto- rielle}

Une caractéristique des régions intertropicales, notamment en Afrique, est un climat favorable à un grand nombre d'arthropodes qui sont vecteurs de maladies infectieuses. Nous abordons ici des pathogènes transmis par des tiques et des insectes. Ce mode de transmission obligatoire rend leur écologie et la réalisation des cycles épidémiologiques très sensibles aux conditions environnementales et à leurs changements.

\section{1 / Trypanosomes et glossines}

L'Afrique connaît une grande diversité écologique, les grands biomes africains du désert du Sahara à la forêt dense humide du bassin du Congo constituant autant d'environnements cloisonnés par des barrières naturelles à l'intérieur desquelles des pathosystèmes ont pu s'installer et se différencier au fil du temps, comme celui des trypanosomoses africaines animales et humaines. Les trypanosomes sont transmis par des glossines à une grande variété d'hôtes vertébrés dont les bovins causant le nagana, et l'Homme, causant la maladie du sommeil. Malgré plus d'un siècle de lutte et la disparition de nombreux biotopes favorables après les grandes sécheresses ayant sévi sur le continent depuis les années 60 , les glossines restent largement répandues en Afrique (figure 2). De vastes zones favorables à l'élevage des ruminants restent sous-exploitées (figure 3). Les pertes économiques annuelles liées à la nagana ont été estimées à 4,5 milliards USD et la maladie du sommeil tue plus de 50000 personnes chaque année (Kabayo 2002). Des travaux récents ont montré que des habitats situés en dehors des zones a priori favorables, comme la région des Niayes au Sénégal, peuvent rester infestées de glossines et de trypanosomes bien qu'elles soient isolées des populations voisines (Bouyer et al 2010). De plus, la fragmentation de l'habitat des glossines n'aboutit pas toujours à leur disparition car elles peuvent s'adapter à ces nouvelles conditions, et permettre une transmission efficace des parasites même si les formes 
Figure 3. Densité des populations bovines (a) et ovines (b) en Afrique, prédites par le modèle de densité de Robinson et al (2007). L'échelle des densités est donnée en bas des cartes.

(a) Bovins

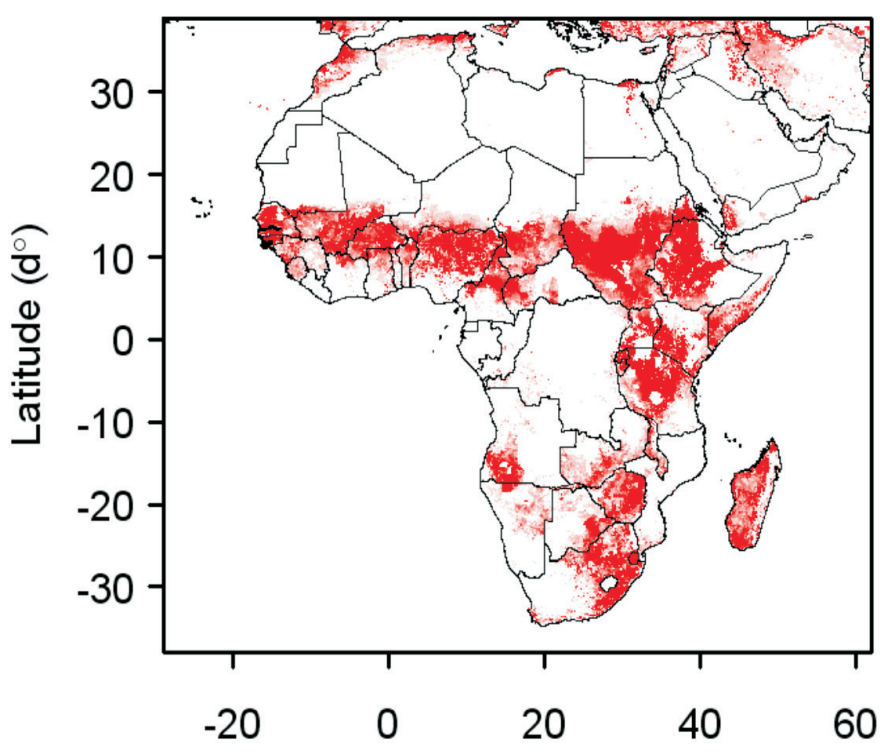

Longitude $\left(\mathrm{d}^{\circ}\right)$

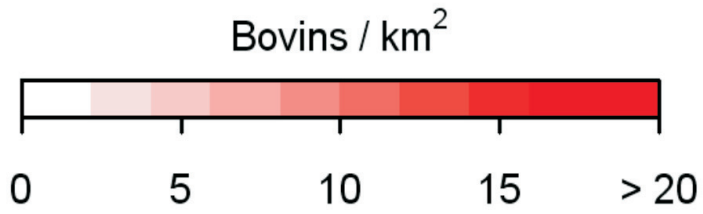

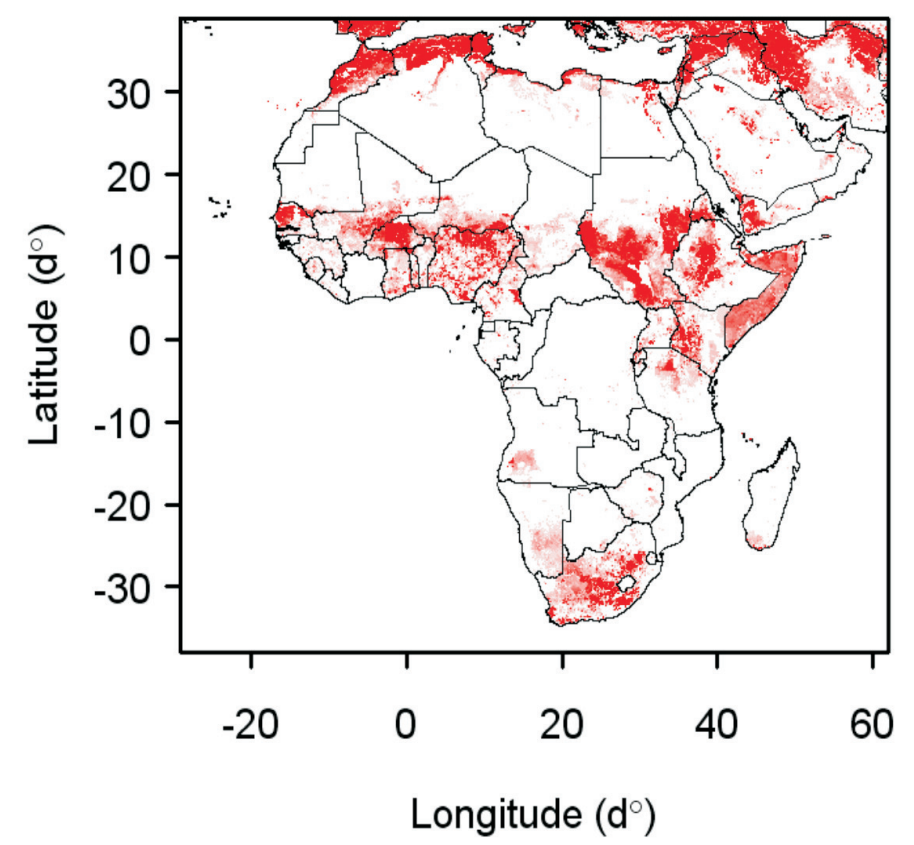

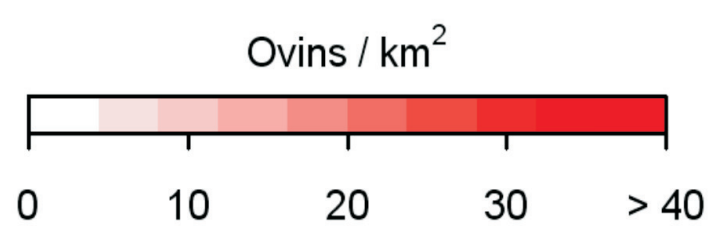

épidémiologiques initiales sont modifiées (Van den Bossche et al 2010). De vastes programmes de lutte ont été entrepris, tels que Pan African Tsetse and Trypano-Somiasis Eradication Campaign (PATTEC) qui vise à éradiquer d'Afrique les glossines et trypanosomoses qu'elles transmettent (Kabayo 2002). Plusieurs méthodes de lutte sont intégrées : écrans attractifs imprégnés d'insecticides pour réduire les populations, appâts vivants (bovins porteurs d'insecticides) pour toucher les glossines dans leurs gites au moment de leur repas sanguin, et enfin lâchers massifs et répétés de mouches mâles stérilisées pour éteindre la population naturelle par compétition reproductrice avec les mâles sauvages (Vreysen 2001). Cette lutte intégrée a permis d'éradiquer les glossines de l'île de Zanzibar, au large de la Tanzanie (Vreysen et al 2000). Cependant, l'ampleur et la coordination des moyens à mettre en œuvre sont radicalement différentes à l'échelle du continent africain, ce qui peut faire douter de la réussite de cette campagne de masse (Rogers et Randolph 2002).

\section{2 / Virus de la fièvre de la Vallée du Rift et moustiques}

La fièvre de la Vallée du Rift (FVR) est une autre maladie à transmission vectorielle d'origine africaine. C'est une zoonose majeure, l'Homme se contaminant au contact d'animaux virémiques, au moment des avortements, de règle dans les populations de ruminants naïves vis-à-vis du virus, ou lors des abattages effectués dans des conditions de biosécurité insuffisantes. Les éleveurs, bouchers, employés d'abattoir, auxiliaires d'élevage et vétérinaires sont particulièrement exposés. Cette arbovirose, transmise par de nombreux moustiques des genres Aedes et Culex en particulier, est causée par un Phlebovirus. A l'origine, un cycle sauvage se déroulait, vraisemblablement en zone forestière, entre moustiques et faune sauvage. Des travaux récents utilisant l'évolution du génome viral comme horloge moléculaire suggèrent que l'ancêtre commun des virus de la FVR (VFVR) remonte à la fin du 19 ème siècle, période à laquelle de nombreux fronts pionniers ont été créés en zone forestière pour l'exploitation du bois et le développement de l'élevage bovin (Bird et al 2007).

La transmission du VFVR par des moustiques rend son cycle épidémiologique sensible aux conditions environnementales. Certaines espèces d'Aedes sont d'ailleurs capables de transmission transovarienne du VFVR, et leurs œufs résistent à la dessiccation consécutive à l'assèchement des gites de ponte. Quand ces gites sont à nouveau inondés (saisons pluvieuses ultérieures), les œufs donnent naissance à des larves puis des adultes déjà infectés et susceptibles d'initier un nouveau cycle, éventuellement amplifié par les Culex si les pluies sont persistantes. Le virus a ainsi pu coloniser les régions semi-arides d'Afrique de l'Est, soumises à l'influence du phénomène météorologique El Niño (Black 2005). Lors de ces épisodes, les pluies automnales sont très abondantes et donnent lieu à des pullulations extraordinaires de moustiques dans les dambos, mares temporaires autour desquelles se rassemblent les populations humaines et leurs ruminants domestiques. Le risque d'épidémie est alors élevé. Ce processus est bien connu et des modèles prédictifs des épidémies de FVR en Afrique de l'Est ont été développés (Linthicum et al 1999). Ils sont utilisés pour émettre des bulletins d'alerte précoce en cas de risque élevé (Anyamba et al 2006). Cependant, malgré la disponibilité d'un vaccin et de recommandations de plan de contingence (Geering et al 2003), les services vétérinaires des pays concernés ne parviennent pas à mettre en place des campagnes de vaccination des ruminants domestiques, seul moyen efficace 
de briser le cycle épidémiologique du VFVR avant l'apparition de cas humains.

D'autre part, les conditions environnementales ne peuvent expliquer la dissémination à longue distance du VFVR, assurée par les mouvements de dromadaires, bovins et petits ruminants, des facteurs liés à la mobilité des troupeaux interagissant avec les facteurs liés à l'environnement dans la diffusion de l'infection. Ainsi, les épidémies survenues en Egypte en 1977 ou sur la péninsule arabe en 2000 étaient consécutives à des importations d'animaux sur pied (Meegan et al 1979, Balkhy et Memish 2003). Il en est de même pour le premier épisode de FVR sur l'île française de Mayotte en 2007-2008 (Pépin et al 2009). Ce risque d'introduction du VFVR par le commerce d'animaux a fréquemment abouti à des interdictions d'importations en provenance des pays infectés entre le Mali et l'Algérie, le Soudan et l'Egypte, et la Corne de l'Afrique et la péninsule arabe, avec des conséquences économiques parfois considérables pour les pays exportateurs. Ainsi, l'interdiction des importations d'ovins de la région somalie de l'Ethiopie par l'Arabie Saoudite suite à l'épidémie de FVR de 2000 s'est soldée par une réduction du produit intérieur brut de cette région de 135 millions USD (36\%) (Pratt et al 2005).

\section{3 / Perspectives en matière de santé animale}

\section{1 / Facteurs de changement et d'émergence}

L'Afrique subit de profondes mutations écologiques, économiques, et sociales dont l'urbanisation et l'accroissement démographique ne sont pas les moindres. De moins de 800 millions de personnes en 2000, la population totale du continent devrait passer à environ 1,5 milliards en 2030, période à laquelle son taux d'urbanisation devrait dépasser $50 \% \quad(40 \%$ en 2010). En Afrique, les agglomérations de plus de 2000 habitants sont toutefois considérées comme des villes (Cohen 2004, United Nations 2009) alors qu'elles sont pour la plupart intimement imbriquées dans le milieu rural, et que l'élevage urbain et périurbain continue de jouer un rôle économique et nutritionnel majeur. $\mathrm{Au}$ Sénégal, par exemple, les plus fortes densités et effectifs d'ovins sont trouvées dans la commune de Pikine, dans la banlieue de Dakar (l'agglomération compte plus de 2 millions d'habitants). D'autre part, une des spécificités essentielles de l'urbanisation africaine (comparée à celle de l'Asie et de l'Amérique latine) est sa marginalisation dans l'économie mondiale. Les villes se développent dans de mauvaises conditions économiques et avec peu d'investissements. Cela rend difficile la mise à disposition pour leurs habitants des services de base : logements, assainissement, éducation, accès aux soins, etc. (Cohen 2004). En d'autres termes, cette croissance urbaine correspond trop souvent à des bidonvilles qui exposent les populations à de multiples risques sanitaires, y compris zoonotiques. Selon les zones agro-écologiques, il est plausible de voir des épizooties et épidémies se développer dans ce type de milieu urbanisé, comme la PPR, la FVR ou les trypanosomoses humaines ou animales (De Deken et al 2005, Simo et al 2006). Les changements climatiques risquent d'accentuer la fréquence et la gravité des crises sanitaires. Il convient cependant d'être prudent dans l'évaluation de ces risques : beaucoup d'hypothèses alarmistes ne résistent pas à une analyse s'appuyant sur des données de terrain et climatiques solides, comme c'est le cas avec le paludisme et des maladies zoonotiques transmises par des moustiques (Hay et al 2002, Reiter 2008). Toutefois, selon les prévisions des modèles climatiques alimentés par des scénarios d'émissions de gaz à effet de serre définis par le Groupe d'Experts Intergouvernemental sur l'Evolution du Climat (GIEC 2007), il est probable que l'Afrique connaisse une diminution des précipitations en zones sahéliennes, méditerranéennes et d'Afrique australe, aboutissant à une chute des rendements agricoles. Cela pourrait accentuer l'exode rural en cours et modifier en profondeur les systèmes d'élevage, notamment de ruminants. L'élevage bovin devrait diminuer au profit de celui des petits ruminants (Seo et Mendelsohn 2007, Seo et al 2008), et les flux commerciaux d'animaux pourraient s'accentuer entre zones de production et de consommation : Afrique subsaharienne et Afrique du Nord, par exemple. On peut s'attendre à une augmentation du risque d'introduction de nouveaux pathogènes dans des zones actuellement indemnes, entre autres, de PPR ou de PPCC, ainsi qu'à une augmentation du risque zoonotique (FVR...) en Afrique du Nord ou sur la péninsule arabe. Par exemple, l'Arabie Saoudite importe chaque année des millions de petits ruminants sur pied depuis la Corne de l'Afrique et a connu des épidémies de FVR en conséquence (Balkhy et Memish 2003, Davies 2006).

D'autre part, il est possible que la diminution de la pluviométrie entraîne la rupture de stabilité de situations épidémiologiques. Les modèles climatiques du GIEC prédisent un accroisse- ment de la fréquence et de l'amplitude des phénomènes extrêmes (sécheresses, inondations) en Afrique de l'Est, en relation avec l'occurrence d'évènements El Niño. Les épidémies de FVR et autres maladies transmises par des moustiques pourraient ainsi être plus fréquentes.

En réponse à l'accroissement de sa démographie, et aux besoins mondiaux en céréales et autres produits agricoles, l'Afrique sera amenée à réaliser de vastes aménagements hydro-agricoles qui se feront au détriment d'espaces pastoraux ou forestiers. Ces fronts pionniers bouleverseront les écosystèmes naturels et mettront de nouveaux pathogènes au contact des animaux domestiques et de l'Homme. De tels événements se sont produits par le passé : la première épidémie de FVR en Egypte (1977-78) est consécutive à l'aménagement du barrage d'Assouan et au développement de cultures irriguées qui ont permis la pullulation de moustiques, puis à l'introduction du virus par le commerce de bétail en provenance du Soudan où sévissait une épidémie (Meegan et al 1979, Eisa et al 1980). Un phénomène analogue a été observé dans la Vallée du fleuve Sénégal à partir de 1987 : la mise en eau du barrage de Diama, construit pour empêcher les remontées d'eau de mer en amont, a rapidement changé l'agro-écosystème du delta du fleuve et les habitudes des éleveurs. Il s'en est suivi de sévères épizooties et épidémies de FVR et schistosomoses humaines et animales (Diaw et al 1998, Jouan et al 1990, Talla et al 1990).

\section{2 / Moyens d'amélioration}

Les conditions socio-économiques et la faiblesse des services vétérinaires africains rendent le continent africain vulnérable aux épizooties et maladies émergentes, dans la mesure où il cumule les spécificités des pathosystèmes en régions chaudes et les difficultés des pays en développement. Un effort international est nécessaire pour améliorer cette situation d'autant que les exemples présentés montrent que l'Afrique n'est pas à l'écart des circuits de diffusion des agents pathogènes à l'échelle mondiale. Elle en a souffert de longue date (introduction de la peste bovine, de la PPCB...) et a été la source d'émergences au Moyen-Orient, en Europe ou ailleurs (fièvre catarrhale ovine, FVR, peste équine, PPA...).

\section{a) Les structures}

La sécurisation sanitaire des échanges d'animaux et de produits animaux est l'objectif majeur du renforcement des collaborations entre l'OIE et la FAO, notamment par le Global Framework 
Figure 4. Centres régionaux de santé animale OIE/FAO et régions de compétence sur le continent africain.

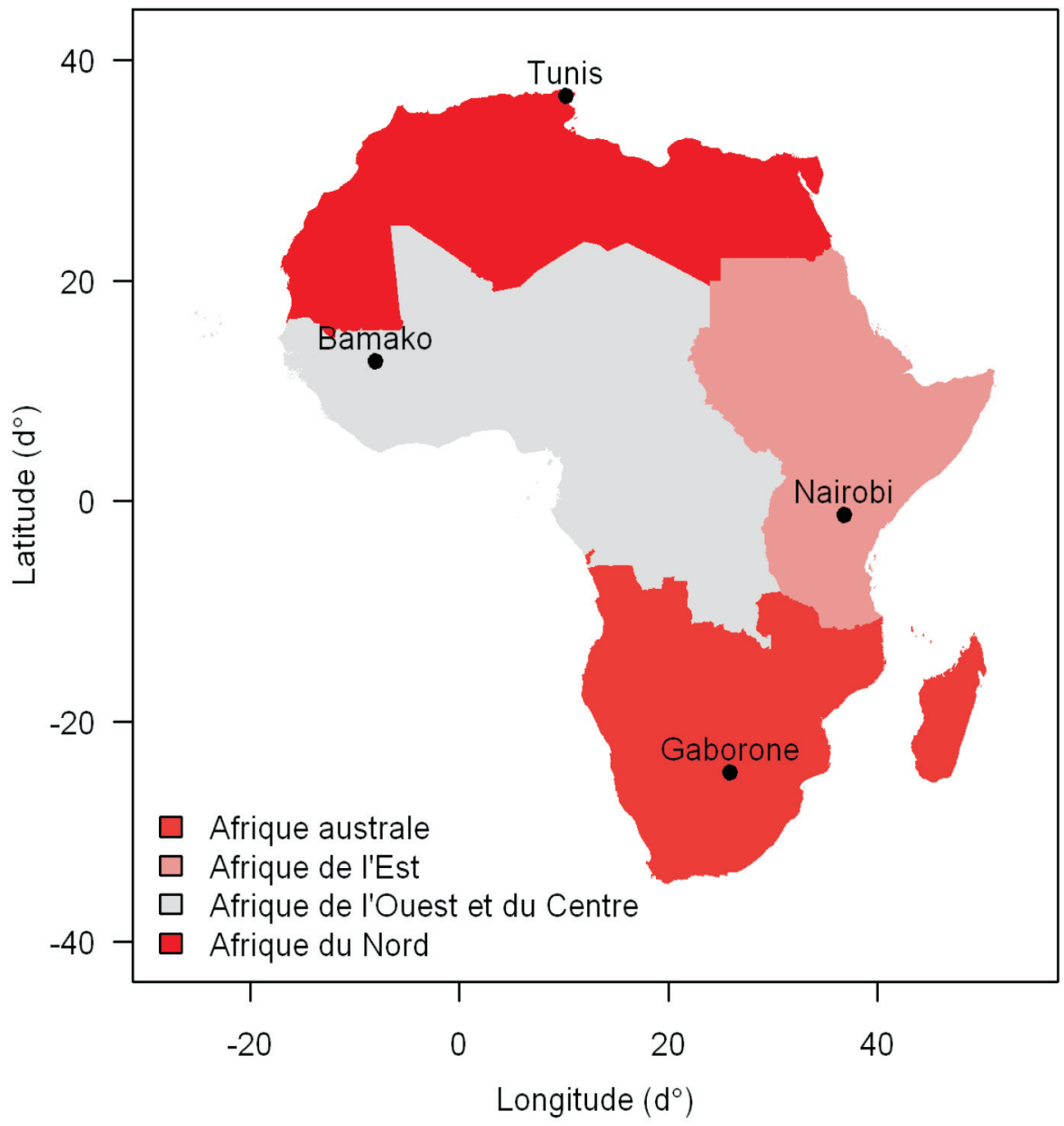

for the Progressive Control of Transboundary Animal Diseases (GF-TADs). Des Centres Régionaux de Santé Animale (CRSA) ont été créés à l'initiative de l'OIE, de la FAO et du Bureau Interafricain des Ressources Animales de l'Union Africaine (UABIRA) en Afrique du Nord, de l'Est, australe, et de l'Ouest et du Centre (figure 4). Ce zonage a été fait en cohérence avec les organisations politiques et économiques régionales. Pour atteindre l'objectif de sécurisation sanitaire des échanges, les CRSA apportent un appui scientifique et technique aux services vétérinaires nationaux : harmonisation et coordination des actions de surveillance et de contrôle des maladies animales.

Cette approche régionale bénéficie de l'appui de centres régionaux de recherche et de formation en santé animale. En Afrique de l'Ouest et du Centre, on peut citer l'Ecole Inter-états des Sciences et Médecine Vétérinaires (EISMV) de Dakar (14 pays membres de la sous-région). Outre des activités d'enseignement et de formation de base de vétérinaires africains, l'EISMV propose différents masters y compris en
L'une d'entre elles («Contrôle des maladies animales exotiques et émergentes») a formé une Unité Mixte de Recherche (UMR) avec l'INRA. D'une manière générale, les axes d'intervention des unités du CIRAD sont : i) recherche en partenariat pour répondre à des questions définies conjointement avec les partenaires du Sud ; ii) expertise et référence en appui aux réseaux de surveillance, services vétérinaires et organisations régionales et internationales (OIE, FAO, UA-BIRA...) et iii) enseignement et formation : intervention dans des masters ou formations professionnelles, encadrement d'étudiants, etc.

Enfin, des structures régionales et continentales ont été mises en place pour définir des priorités de recherche et constituer des forums de discussion en interface avec les producteurs africains, SNRA, centres internationaux de recherche, et bailleurs de fonds de la recherche agronomique. Il s'agit du Conseil Ouest et Centre Africain pour la Recherche et le Développement Agricoles (CORAF), de l'Association for Strengthening Agricultural Research in Eastern and Central Africa (ASARECA) et du Forum Africain pour la Recherche Agricole (FARA).

\section{b) Méthodes et stratégies}

Jusqu'à présent, la santé animale, considérée comme trop spécifique ou indépendante des grandes questions socio-économiques, n'a pas été au cœur des préoccupations des bailleurs de fonds internationaux. Nombre de pathogènes ont cependant une importance économique considérable, par les pertes directes qu'ils occasionnent (peste bovine, PPCB...) et les restrictions aux échanges commerciaux qui résultent des épidémies, comme pour la FVR (voir l'encadré sur l'impact socio-économique des maladies animales). D'autre part, l'importance pour la santé publique de certaines zoonoses est considérable. Il revient donc aux chercheurs de formuler leurs questions et projets de recherche sous une forme montrant clairement le lien de la santé animale avec les préoccupations internationales, telles que l'impact des évolutions démographiques ou des changements climatiques et environnementaux sur le développement économique et social des pays en développement.

Pour améliorer significativement la santé animale et la santé publique, il est avant tout nécessaire d'avoir une connaissance précise de la situation sanitaire et de son évolution, en s'appuyant sur des données objectives de terrain. Cela passe par le développement de réseaux nationaux et régionaux de 
Encadré. Impact socio-économique des maladies animales dans les pays du Sud.

La capacité des populations à acquérir des animaux de production est limitée par leur valeur sur le marché, alors qu'environ deux tiers des personnes vivant avec moins de 2 USD par jour élèvent des animaux comme moyen d'existence (Heffernan 2009). Ainsi peut-on établir une sorte de hiérarchie des espèces animales, depuis la volaille dont l'élevage familial ou villageois est très majoritaire, jusqu'aux grandes espèces (bovinés) qui peuvent être indispensables à un statut social, en passant par les porcs et les petits ruminants, selon les régions (Perry et al 2002).

Comme dans les pays du Nord, les maladies animales ont un impact sur la viabilité économique des exploitations d'élevage (pertes de production, coûts de prévention ou de traitement, etc.) et des filières de production animales. A cela s'ajoutent d'autres conséquences spécifiques aux pays du Sud, liées à l'extrême vulnérabilité des populations et au fait que l'animal joue d'autres rôles que dans notre société.

Dans les systèmes traditionnels, «la ponction continue exercée par les maladies infectieuses et parasitaires endémiques sur la production et la productivité réduit la capacité des petits exploitants à sortir de la pauvreté» (FAO 2009), et peut être dans certains cas à l'origine de pénuries alimentaires. Par ailleurs, l'animal sert de force motrice pour le trait et le labour. Les maladies débilitantes pour le bétail, par exemple la PPCB, ont un impact d'autant plus fort qu'elles touchent les animaux de trait, obérant par la même la possibilité de cultiver. Enfin, le cheptel constitue un capital sur pied : "pour de nombreuses familles du quintile le plus pauvre, les maladies animales sont particulièrement dommageables parce qu'elles menacent le bien même qui leur sert à faire face à d'autres crises» (FAO 2009). Pour toutes ces raisons, "l'amélioration de la gestion de l'élevage, en vue de prévenir et de maîtriser ces maladies, peut être porteuse de bienfaits économiques, sociaux et sanitaires pour les pauvres et pour l'ensemble de la société» (FAO 2009).

surveillance, impliquant les producteurs, les services vétérinaires et les laboratoires de diagnostic, y compris les laboratoires internationaux de référence, avec l'appui d'organisations régionales et internationales. Le chemin est long et difficile pour parvenir à des résultats satisfaisants, mais des exemples de réussite existent, comme le réseau CaribVet dans la région Caraïbe (Lefrancois et al 2010).

Ces réseaux doivent bénéficier d'outils performants de diagnostic. Des progrès considérables ont été faits ces dernières années avec la popularisation des méthodes et outils moléculaires. Beaucoup reste à faire en matière de tests de diagnostic rapide «au chevet des malades», et en développement de plates-formes africaines de diagnostic à haut débit, permettant de traiter rapidement de nombreux prélèvements, avec des résultats exploitables en épidémiologie moléculaire. Ces nouveaux outils de diagnostic nécessiteront une révision des concepts et méthodes de la surveillance épidémiologique, en particulier pour l'échantillonnage.

La surveillance épidémiologique n'a de sens que si elle est adossée à des programmes de contrôle des maladies animales et zoonotiques. Le développement de nouveaux vaccins est un passage obligé : FVR, PPA, PPCB et PPCC, PPR, etc. Ils seront de préférence multivalents pour limiter la manipulation des animaux, et permettront de différencier les réponses immunitaires dues aux infections naturelles ou consécutives aux vaccinations. Outre les aspects scientifiques, un obstacle majeur à leur développement est le manque d'intérêt des compagnies pharmaceutiques compte tenu de la faible taille économique des marchés concer- nés. La recherche et les investissements sont surtout supportés par la recherche publique (internationale) compte tenu du manque de moyens des états du continent. La situation s'améliore progressivement avec des plates-formes de concertation public-privé (European technology platform for global animal health), ou quelques fondations Wellcome Trust, Bill \& Melinda Gates, etc. Cependant, certains dossiers comme les recherches sur un vaccin contre la PPCB, avancent lentement.

Enfin, le vaccin n'est pas tout : il s'est passé 50 ans entre la mise au point de l'excellent vaccin antipestique de Plowright et l'éradication de la peste bovine. Il s'agit donc de définir des programmes de lutte intégrée, utilisant toutes les possibilités de la prophylaxie médicale et sanitaire, avec une forte composante participative des éleveurs et auxiliaires d'élevage. Ces programmes seront forcément régionaux et coordonnés à l'échelle africaine, pour avoir une chance de réussite. La communauté internationale des chercheurs, notamment africains et européens, devra se faire entendre pour que ces programmes régionaux soient construits sur des bases scientifiques et techniques cohérentes.

\section{Conclusion et perspectives}

L'élevage en Afrique est confronté à des maladies animales, pour certaines dues aux mêmes agents pathogènes que ceux observés en Europe, mais dont le contrôle s'avère difficile. Il y a plusieurs raisons à cela, liées d'une part au contexte humain et socio-économique, et d'autre part aux particularités climatiques et environnementales. La premiè- re raison est mise en évidence par la persistance de certaines maladies infectieuses majeures, par exemple la PPCB, en Afrique alors qu'elles ont pu être éradiquées en Europe en s'appuyant sur les mêmes méthodes et outils. En effet, la difficulté de les contrôler en Afrique résulte de l'importance des mouvements d'animaux liés à la transhumance et au commerce transfrontaliers, mais aussi à l'insuffisance des moyens alloués aux services vétérinaires pour mettre en œuvre de manière efficace des actions de sensibilisation et de contrôle de ces maladies. Une difficulté supplémentaire est d'obtenir la participation effective des populations pauvres, dépendant de leurs animaux d'élevage pour leur subsistance. Toutefois l'éradication de la peste bovine a montré qu'un investissement de long terme de la communauté internationale, scientifiquement et techniquement fondé, bien coordonné, avec un effort considérable des services vétérinaires nationaux et des éleveurs, pouvait aboutir à un résultat exemplaire. $\mathrm{La}$ deuxième raison relève des conditions climatiques et environnementales de ces régions chaudes, favorables à un ensemble de parasites et d'arthropodes vecteurs d'agents pathogènes de maladies infectieuses et parasitaires, difficiles à contrôler sans bouleverser leurs écosystèmes d'occurrence. A l'inverse, une modification des agro-écosystèmes peut permettre une adaptation du vecteur (glossines dans certaines zones qui leur sont devenues défavorables), ou même entraîner une extension de son habitat (moustiques en zones irriguées).

Du point de vue des pays du Nord, la présence de ces maladies au Sud représente un risque constant d'introduction d'agents pathogènes et de vecteurs, par les voyages (PPA introduite en 1957 au Portugal par des eaux grasses en provenance du Mozambique), ou à cause des modifications climatiques favorisant l'arrivée de vecteurs de maladies en Europe (invasion du sud de l'Europe par Culicoides imicola, moucheron piqueur vecteur des virus de la fièvre catarrhale ovine et de la peste équine). La situation sanitaire ne pourra être améliorée que par une approche scientifique, technique, économique et sociale adaptée et ciblée. Elle devrait s'appuyer sur des réseaux de surveillance et de recherche afin de mieux apprécier les évolutions épidémiologiques, et de disposer d'outils de diagnostic et de contrôle (vaccins, insecticides...) plus efficaces. Cette stratégie de lutte intégrée avec une coordination continentale et internationale devrait être appuyée par les pays du Nord, pour le bénéfice des pays du Sud et de l'ensemble de la planète. 


\section{Références}

Abdelwhab E.M., Selim A.A., Arafa A., Galal S., Kilany W.H., Hassan M.K., Aly M.M., Hafez M.H., 2010. Circulation of avian influenza $\mathrm{H} 5 \mathrm{~N} 1$ in live bird markets in Egypt. Avian Dis., 54, 911-914.

Abraham G., Sintayehu A., Libeau G., Albina E., Roger F., Laekemariam Y., Abayneh D., Awoke K., 2005. Antibody seroprevalences against Peste des Petits Ruminants (PPR) virus in camels, cattle, goats and sheep in Ethiopia. Prev. Vet. Med., 70, 51-57.

Alary V., 2006. Desk review. Étude du commerce régional du bétail et des produits animaux en Afrique de l'Ouest (Zone Ecowas) et Afrique de l'Est (Zone IGAD). CIRAD (Ed). Montpellier, FAO/OIE, Rome, Italie, 136p.

Aly M.M., Arafa A., Hassan M.K., 2008. Epidemiological findings of outbreaks of disease caused by highly pathogenic $\mathrm{H} 5 \mathrm{~N} 1$ avian influenza virus in poultry in Egypt during 2006. Avian Dis., 52, 269-277.

Anyamba A., Chretien J.P., Small J., Tucker C.J., Linthicum K.J., 2006. Developing global climate anomalies suggest potential disease risks for 2006-2007. Int. J. Health Geogr., 5, 60 .

AU-IBAR, 2011. Impact of livestock diseases in Africa. African Union (AU) Interafrican Bureau for Animal Resources ( A U - I B A R ). ht t p: // w w w a u ibar.org/index.php/en/projects/currentprojects/vacnada/livestock-diseases. Accès 2011.03 .22

Ayari-Fakhfakh E., Ghram A., Bouattour A., Larbi I., Gribâa-Dridi L., Kwiatek O., Bouloy M., Libeau G., Albina E., Cêtre-Sossah C., 2011. First serological investigation of peste des petits ruminants and Rift Valley fever in Tunisia. Vet. J., 187, 402-404

Balkhy H.H., Memish Z.A., 2003. Rift Valley fever: an uninvited zoonosis in the Arabian peninsula. Int. J. Antimicrob. Agents, 21, 153-157.

Bastos A.D., Boshoff C.I., Keet D.F., Bengis R.G., Thomson G.R., 2000. Natural transmission of foot-and-mouth disease virus between African buffalo (Syncerus caffer) and impala (Aepyceros melampus) in the Kruger National Park, South Africa. Epidemiol. Infect., 124, 591-598.

Bird B.H., Khristova M.L., Rollin P.E., Ksiazek T.G., Nichol S.T., 2007. Complete genome analysis of 33 ecologically and biologically diverse Rift Valley fever virus strains reveals widespread virus movement and low genetic diversity due to recent common ancestry. J. Virol., 81, 2805-2816.

Black E., 2005. The relationship between Indian Ocean sea-surface temperature and East African rainfall. Philos. Transact. A Math Phys. Eng. Sci., 363 (1826), 43-47.

Bouyer J., Seck M.T., Sall B., Ndiaye E.Y., Guerrini L., Vreysen M.J.B., 2010. Stratified entomological sampling in preparation for an area-wide integrated pest management program: the example of Glossina palpalis gambiensis (Diptera: Glossinidae) in the Niayes of Senegal. J. Med. Entomol., 47, 543-552.

Bwala D.G., Abolnik C., van Wyk A., Cornelius E., Bisschop S.P.R., 2009. Efficacy of a genotype 2 Newcastle disease vaccine (Avinew) against challenge with highly viru- lent genotypes 5d and 3d. J. S. Afr. Vet. Assoc., $80,174-178$.

Cattoli G., Monne I., Fusaro A., Joannis T.M., Lombin L.H., Aly M.M., Arafa A.S., Sturm-Ramirez K.M., Couacy-Hymann E., Awuni J.A., Batawui K.B., Awoume K.A. Aplogan G.L., Sow A., Ngangnou A.C., El Nasri Hamza I.M., Gamatié D., Dauphin G. Domenech J.M., Capua I., 2009. Highly pathogenic avian influenza virus subtype $\mathrm{H} 5 \mathrm{~N} 1$ in Africa: a comprehensive phylogenetic analysis and molecular characterization of isolates. PLoS ONE, 4, e 4842 .

Cattoli G., Fusaro A., Monne I., Molia S., Le Menach A., Maregeya B., Nchare A., Bangana I., Garba Maina A., N'Goran Koffi J.N., Thiam H., Bezeid O.E.M.A., Salviato A., Nisi R. Terregino C., Capua I., 2010, Emergence of a new genetic lineage of Newcastle disease virus in West and Central Africa. Implications for diagnosis and control. Vet. Microbiol., 142, 168-176.

Cohen B., 2004. Urban growth in developing countries: a review of current trends and a caution regarding existing forecasts. World Dev., 32, 23-51

Couacy-Hymann E., Bodjo C., Danho T. Libeau G., Diallo A., 2005. Surveillance of wildlife as a tool for monitoring rinderpest and peste des petits ruminants in West Africa. Rev. Sci. Tech., 24, 869-877.

Davies F., 2006. Risk of a Rift Valley fever epidemic at the haj in Mecca, Saudi Arabia. Rev. Sci. Tech., 25, 137-147.

De Deken R., Sumbu J., Mpiana S., Mansinsa P., Watsenga F., Lutumba P., Boelaer M., Van den Bossche P., 2005. Trypanosomiasis in Kinshasa: distribution of the vector, Glossina fuscipes quanzensis, and risk of transmission in the peri-urban area. Med. Vet. Entomol., 19, 353-359.

Diallo A., Taylor W.P., Lefèvre P.C., Provost A., 1989. Atténuation dune souche de virus de la peste des petits ruminants: candidat pour un vaccin homologue vivant. Rev. Elev. Méd. Vét. Pays Trop., 42, 311-319.

Diaw O., Vassiliadès G., Thiongane Y., Seye M., Sarr Y., Diouf A., 1998. Extension des trématodoses du bétail après la construction des barrages dans le bassin du fleuve Sénégal. Rev. Elev. Méd. Vét. Pays Trop., 51, 113-120.

Eisa M., Kheir El Sid E., Meegan J., 1980. An outbreak of Rift Valley fever in the Sudan1976. Trans. R. Soc. Trop. Med. Hyg., 74, 417 418

El Hicheri K., Gomez-Tejedor C., Penrith M.L., Davies G., Douati A., Edoukou G.J., Wojciechowski K., 1998. L'épizootie de peste porcine africaine de 1996 en Côte d'Ivoire. Rev. Sci. Tech., 17, 660-673.

FAO, 2009. La situation mondiale de l'alimentation et de l'agriculture : Le point sur l'élevage. FAO, Rome, Italie, 186p.

Fasina F.O., Bisschop S.P.R., Joannis T.M., Lombin L.H., Abolnik C., 2009. Molecula characterization and epidemiology of the highly pathogenic avian influenza H5N1 in Nigeria. Epidemiol. Infect., 137, 456-463.

Gaidet N., Cappelle J., Takekawa J., Prosser D., Iverson S., Douglas D., Perry W., Mundkur T., Newman S., 2010. Potential spread of highly pathogenic avian influenza H5N1 by wild- fowl: dispersal ranges and rates determined from large-scale satellite telemetry. J. Appl. Ecol. Early View, 1-11.

Geering W., Davies E., Martin V., 2003. Préparation des plans d'intervention contre la fièvre de la Vallée du Rift. In : Manuel FAO de santé animale. Organisation des Nations Unies pour l'Alimentation et l'Agriculture, Rome, Italie, $77 \mathrm{p}$.

GIEC, 2007. Bilan 2007 des changements climatiques. Contribution des Groupes de travail I, II et III au quatrième Rapport d'évaluation du Groupe d'experts intergouvernemental sur l'évolution du climat. Genève, 103p.

Guan Y., Smith G.J.D., Webby R., Webster R.G., 2009. Molecular epidemiology of H5N1 avian influenza. Rev. Sci. Tech., 28, 39-47.

Hafez M.H., Arafa A., Abdelwhab E.M. Selim A., Khoulosy S.G., Hassan M.K., Aly M.M., 2010. Avian influenza H5N1 virus infections in vaccinated commercial and backyard poultry in Egypt. Poult. Sci., 89, 1609-1613.

Hargreaves S.K., Foggin C.M., Anderson E.C., Bastos A.D.S., Thomson G.R., Ferris N.P., Knowles N.J., 2004. An investigation into the source and spread of foot and mouth disease virus from a wildlife conservancy in Zimbabwe. Rev. Sci. Tech., 23, 783-790.

Hassan W., Khair S.A.M., Mochotlhoane B., Abolnik C., 2010. Newcastle disease outbreaks in the Sudan from 2003 to 2006 were caused by viruses of genotype $5 \mathrm{~d}$. Virus Genes, 40, 106110.

Hay S.I., Cox J., Rogers D.J., Randolph S.E., Stern D.I., Shanks G.D., Myers M.F., Snow R.W., 2002. Climate change and the resurgence of malaria in the East African highlands. Nature, 415, 905-909.

Heffernan C., 2009. Panzootics and the poor: devising a global livestock disease prioritisation framework for poverty alleviation. Rev. Sci. Tech., 28, 897-907.

Hübschle O., Aschenborn O., Godinho K., Nicholas R., 2006. Control of CBPP, a role for antibiotics? Vet. Rec., 159, 464.

Jori F., Bastos A.D.S., 2009. Role of wild suids in the epidemiology of African swine fever. EcoHealth, 6, 296-310.

Jouan A., Adam F., Coulibaly I., Riou O., Philippe B., Ledru E., Le Jan C., Merzoug N., Ksiazek T., Le Guenno B., 1990. Epidemic of Rift Valley fever in the Islamic republic of Mauritania. Geographic and ecological data. Bull. Soc. Pathol. Exot., 83, 611-620.

Kabayo J.P., 2002. Aiming to eliminate tsetse from Africa. Trends Parasitol., 18, 473475 .

Khalafalla A.I., Saeed I.K., Ali Y.H., Abdurrahman M.B., Kwiatek O, Libeau G, Abu Obeida I., Abbas Z., 2010. An outbreak of Peste des Petits Ruminants (PPR) in camels in the Sudan. Acta Trop., 1-5.

Kim J.K, Kayali G, Walker D, Forrest H.L., Ellebedy A.H., Griffin Y.S., Rubrum A., Bahgat M.M., Kutkat M.A., Ali M.A.A., Aldridge J.R., Negovetich N.J., Krauss S., Webby R.J., Webster R.G., 2010. Puzzling inefficiency of H5N1 influenza vaccines in Egyptian poultry. Proc. Natl. Acad. Sci. USA, 107, 11044-11049. 
Knips V., 2004. Review of the livestock sector in the Horn of Africa (IGAD countries). Rome, Italie, FAO, 42p.

Kock R., Wamwayi H., Rossiter P., Libeau G., Wambwa E., Okori J., Shiferaw F. Mlengeya T., 2006. Re-infection of wildlife populations with rinderpest virus on the periphery of the Somali ecosystem in East Africa. Prev. Vet. Med., 75, 63-80.

Lefrancois T., Petit-Sinturel M., Kalloo M., Shaw J., Herbert-Hackshaw K., Trotman M., Gongora V., 2010. CaribVET: a model for surveillance of zoonotic diseases. Int. J. Inf. Dis., 14 (Suppl. 1), e185-e185.

Linthicum K.J., Anyamba A., Tucker C.J. Kelley P.W., Myers M.F., Peters C.J., 1999. Climate and satellite indicators to forecast Rift Valley fever epidemics in Kenya. Science, 285, $397-400$

Mack R., 1970. The great African cattle plague epidemic of the 1890's. Trop. Anim. Health Prod., 2, 210-219.

Maho A., Gondje N., Mopate L., Kana G., 2004. La maladie de Newcastle au sud du Tchad : périodes de pic épidémique et impact de la vaccination. Rev. Sci. Tech., 23, 777-782.

Maminiaina O.F., Koko M., Ravaomanana J., Rakotonindrina S.J., 2007. Épidémiologie de la maladie de Newcastle en aviculture villageoise à Madagascar. Rev. Sci. Tech., 26, 691700 .

Maminiaina O.F, Gil P., Briand F.X, Albina E., Keita D., Andriamanivo H.R., Chevalier V., Lancelot R., Martinez D., Rakotondravao R., Rajaonarison J.J., Koko M., Andriant-Simahavandy A.A., Jestin V., Servan de Almeida R. 2010. Newcastle disease virus in Madagascar: identification of an original genotype possibly deriving from a died out ancestor of genotype IV. PLoS ONE, 5, e13987.

Mariner J.C., Roeder P. L., 2003. Use of participatory epidemiology in studies of the persistence of lineage 2 rinderpest virus in East Africa. Vet. Rec., 152, 641-647.

Mariner J.C., Jeggo M.H., van't Klooster G.G.M., Geiger R., Roeder P.L, 2003. Rinderpest surveillance performance monitoring using quantifiable indicators. Rev. Sci. Tech., 22, 837-847.

Meegan J.M., Hoogstraal H., Moussa M.I., 1979. An epizootic of Rift Valley fever in Egypt in 1977. Vet. Rec., 105, 124-125.

Mukhopadhyay A.K., Taylor W.P., Roeder P.L., 1999. Rinderpest: a case study of animal health emergency management. Rev. Sci. Tech., 18, 164-178.

Kamuanga M.J.B Somda J., Sanon Y Kagoné H. Zoundi J.S., Hitimana L., 2008. Élevage et marché régional au Sahel et en Afrique de l'Ouest Potentialités et défis. Club du Sahel et de l'Afrique de l'Ouest, OCDE (Ed). 182p.

Nicholas R.A.J., Ayling R. D., McAuliffe L., 2009. Vaccines for Mycoplasma diseases in animals and man. J. Comp. Pathol., 140, 85-96.

Normile D., 2008. Rinderpest: driven to extinction. Science, 319, 1606-1609.

Ogbu O., Ajuluchukwu E., Uneke C.J., 2007. Lassa fever in West African sub-region: an overview. J. Vector Borne Dis., 44, 1-11.

Pépin M., Dampfhoffer M., Chevalier V., Cêtre-Sossah C., 2009. La fièvre de la vallée $\mathrm{du}$ Rift a fait une première incursion à Mayotte, un département français. Bull. Epidémiol. AFSSA, 33, 14

Perry B.D., Randolph T.F., McDermott J.J., Sones K.R., Thornton P.K., 2002. Investing in animal health research to alleviate poverty. ILRI, Nairobi, 148p.

Peyre M., Samaha H., Makonnen Y.J., Saad A., Abd-Elnabi A., Galal S., Ettel T., Dauphin G., Lubroth J., Roger F., Domenech J., 2009. Avian influenza vaccination in Egypt: Limitations of the current strategy. J. Mol. Genet. Med., 3, 198-204.

Plowright W., Ferris R., 1962. Studies with rinderpest virus in tissue culture. The use of attenuated culture virus as a vaccine for cattle. Res. Vet. Sci., 3, 172-182.

Pratt A., Bonnet P., Jabbar M., Ehui S., de Haan C., 2005. Benefits and costs of compliance of sanitary regulations in livestock markets: the case of Rift Valley fever in the Somal region of Ethiopia. ILRI, Nairobi, 64p

Randriamparany T., Grenier A., Tourette I. Maharavo Rahantamalala C., Rousset D. Lancelot R., 2005. Situation épidémiologique de la peste porcine africaine dans la région du lac Alaotra (Madagascar) et conséquences possibles pour l'organisation de la lutte et de la surveillance. Rev. Elev. Méd. Vét. Pays Trop. $58,15-20$.

Ravaomanana J., Michaud V., Jori F. Andriatsimahavandy A., Roger F., Albina E., Vial L., 2010. First detection of African swine fever virus in Ornithodoros porcinus in Madagascar and new insights into tick distribution and taxonomy. Parasit. Vectors, 3, 115.

Reiter P., 2008. Climate change and mosquito-borne disease: knowing the horse before hitching the cart. Rev. Sci. Tech., 27, 383-398.

Robinson T., Franceschini G., Wint G., 2007. The Food and Agriculture Organization's gridded livestock of the world. Vet. Ital., 43, 745 751

Roger F., Guebre Yesus M., Libeau G., Diallo A., Yigezu L., Yilma T., 2001. Detection of antibodies of rinderpest and peste des petit ruminants viruses (Paramyxoviridae, Morbillivirus) during a new epizootic disease in Ethiopian camels (Camelus dromedarius). Rev. Méd. Vét., 152, 265-268.

Rogers D., Randolph S., 2002. A response to the aim of eradicating tsetse from Africa. Trends Parasitol., 18, 534-536.

Rossiter P., Wamwayi H., Ndungu E., 2006. Rinderpest seroprevalence in wildlife in Kenya and Tanzania, 1982-1993. Prev. Vet. Med., 75, $1-7$.

Rousset D., Randriamparany T., Rahantamalala C.Y.M., Randriamahefa N., Zeller H. Rakoto-Andrianarivelo M., Roger F., 2001. Introduction de la peste porcine africaine à Madagascar, histoire et leçons d'une émer gence. Arch. Inst. Pasteur Madagascar, 67, 3133.

Saad M.D., Ahmed L.S., Gamal-Eldein M.A., Fouda M.K., Khalil F., Yingst S.L. Parker M.A., Montevillel M.R., 2007. Possible avian influenza (H5N1) from migratory bird. Egypt. Emerg. Infect. Dis., 13, 1120-1121.

Sandvik T., Crooke H., Drew T.W., Blome S., Greiser-Wilke I., Moennig V., Gous T.A. Gers S., Kitching J.A., Bührmann G., Brückner G.K., 2005. Classical swine fever in South Africa after 87 years' absence. Vet. Rec., 157, 267.
Sanz-Alvarez J., Diallo A., De La Rocque S. Pinto J., Thevenet S., Lubroth J., 2008. Peste des Petits Ruminants (PPR) in Morocco. EMPRES Watch August, 1-7.

Seo S.N., Mendelsohn R., 2007. Climate change impacts on animal husbandry in Africa: a Ricardian analysis. Policy Research Working Paper 4261, Washington, The World Bank, 48p.

Seo S.N., Mendelsohn R., Dinar A. Kurukulasuriya P., 2008. Differential adaptation strategies by agro-ecological zones in African livestock. Policy Research Working Paper 4601, Washington, The World Bank, 39 p.

Shaila M.S., Shamaki D., Forsyth M.A., Diallo A., Goatley L., Kitching R.P., Barrett T., 1996. Geographic distribution and epidemiology of peste des petits ruminants virus. Virus Res., 43, 149-153.

Simo G., Mansinsa Diabakana P., Kande Betu Ku Mesu V., Manzambi E.Z., Ollivier G., Asonganyi T., Cuny G., Grebaut P., 2006. Human African trypanosomiasis transmission, Kinshasa, Democratic Republic of Congo. Emerg. Infect. Dis., 12, 1968-1970.

Swai E.S., Kapaga A., Kivaria F., Tinuga D., Joshua G., Sanka P., 2009. Prevalence and distribution of peste des petits ruminants virus antibodies in various districts of Tanzania. Vet. Res. Commun., 33, 927-936.

Talla I., Kongs A., Verlé P., Belot J., Sarr S., Coll A.M., 1990. Outbreak of intestinal schistosomiasis in the Senegal River Basin. Ann. Soc. Belg. Med. Trop., 70, 173-180.

Thiaucourt F., Dedieu L., Maillard J.C., Bonnet P., Lesnoff M., Laval G., Provost A., 2003. Contagious bovine pleuropneumonia vaccines, historic highlights, present situation and hopes. Dev. Biol., 114, 147-160.

Thiaucourt F., Aboubakar Y., Wesonga H., Manso-Silvan L., Blanchard A., 2004. Contagious bovine pleuropneumonia vaccines and control strategies: recent data. Dev. Biol., $119,99-111$

United Nations, 2009. World urbanization prospects, the 2009 revision. http://esa.un.org/ unpd/wup/index.htm (accessed on line on 28 August 2010).

Van den Bossche P., de La Rocque S. Hendrickx G., Bouyer J., 2010. A changing environment and the epidemiology of tsetsetransmitted livestock trypanosomiasis. Trends Parasitol., 26, 236-243.

Vreysen M.J., 2001. Principles of area-wide integrated tsetse fly control using the sterile insect technique. Méd. Trop., 61, 397-411.

Vreysen M.J., Saleh K., Ali M.Y., Abdulla A.M., Zhu Z.R., Juma K.G., Dyck V.A., Msangi A.R., Mkonyi P.A., Feldmann H.U., 2000. Glossina austeni (Diptera: Glossinidae) eradicated on the island of Unguja, Zanzibar, using the sterile insect technique. J. Econ. Entomol., 93, 123-135.

Wint W., Rogers D., 2000. Predicted distributions of tsetse in Africa. Rome, Italie, FAO, 62 p.

World Health Organization, 2010. Cumulative number of confirmed human cases of avian influenza A/(H5N1) reported to WHO. 12 Aug. 2010. http://www.who.int/csr/disease/ avian influenza/ (accessed on 25 August 2010). 


\title{
Résumé
}

Les spécificités de la santé animale en Afrique, exemple de zone à régions chaudes, tiennent à la fois aux caractéristiques climatiques et environnementales, aux systèmes d'élevage extensifs et à la mobilité animale (transhumance, commerce), ainsi qu'au contexte socioéconomique difficile, avec des services vétérinaires disposant de moyens insuffisants. Les conditions d'élevage et la mobilité animale contribuent à la diffusion de maladies à transmission directe, comme la péripneumonie contagieuse bovine ou la peste des petits ruminants. L'environnement conditionne la biologie des vecteurs (insectes, tiques), donc la diffusion de maladies à transmission vectorielle. Certaines sont spécifiques à l'Afrique, comme les trypanosomoses humaines et animales. D'autres, comme la fièvre de la Vallée du Rift, dont le virus causal est transmis par de nombreuses espèces de moustiques, sont en pleine émergence. Elles sont susceptibles de coloniser d'autres écosystèmes via le commerce de bétail : ainsi cette maladie a été introduite sur la péninsule arabique et s'y est installée. La fragilité socio-économique de l'Afrique la rend plus vulnérable que les autres continents aux émergences de maladies animales, ensuite potentiellement exportables, liées aux changements climatiques et environnementaux, à l'accroissement démographique et à l'intensification des échanges internationaux et des voyages. $L$ 'amélioration de la situation sanitaire passe par la définition et la mise en ouvre au plan régional, avec une coordination continentale et internationale, d'une stratégie de lutte intégrée ; elle devrait s'appuyer sur des réseaux de surveillance et de recherche afin de mieux apprécier les évolutions épidémiologiques, et de disposer d'outils de diagnostic et de contrôle (vaccins, insecticides...) plus efficaces.

\begin{abstract}
Specificity of animal health in the tropics: internationally important infectious diseases of Aftrica

Specific features of animal health in Africa are related to the diversity of climatic and environmental conditions, the predominance of low-input livestock farming systems, the intensity of long-distance animal movements (transhumance, trade), and difficult socioeconomic conditions leading to poorly-funded veterinary services. Livestock farming systems and animal movements enhance the spreading of directly-transmitted diseases such as contagious bovine pleuropneumonia or peste des petits ruminants. Environmental conditions determine the biology of vectors (insects or ticks) and the spreading of vector-borne diseases. Some of them are specific to Africa, like human and animal trypanosomoses transmitted by tsetse flies. Others, like Rift Valley fever (RVF), transmitted by many mosquito species, are emerging. Should the RVF virus be introduced in favourable ecosystems (e.g., through livestock trade), RVF may install in other continents than Africa, like it has already been the case for the Arabic peninsula. The poor socio-economic conditions met in Africa make it more vulnerable than others to emerging or re-emerging animal diseases consecutive to climatic and environmental changes, increasing demography, and more intense travels and international trade. To obtain a substantial improvement of this situation, a regional disease-control strategy must be defined and implemented, with a continental and international coordination. This strategy should rely on integrated disease control with feed-back from national and regional disease surveillance networks, and more efficient tools and methods provided by research partners.
\end{abstract}

LANCELOT R., ZUNDEL E., DUCROT C., 2011. Spécificités de la santé animale en régions chaudes : le cas des maladies infectieuses majeures en Afrique. In : Numéro spécial, Elevage en régions chaudes. Coulon J.B., Lecomte P., Boval M., Perez J.M. (Eds). INRA Prod. Anim., 24, 65-76. 
